\title{
EXISTENCE AND UNIQUENESS FOR NONLINEAR NEUTRAL-DIFFERENTIAL EQUATIONS ${ }^{1}$
}

\author{
BY L. J. GRIMM
}

Communicated by Wolfgang Wasow, August 14, 1970

ABstract. Fixed point theorems are used to prove existence and uniqueness of the $\mathbf{C}^{\mathbf{1}}$ solution of the initial-value problem for a functional-differential equation of neutral type.

1. Introduction. In this paper we consider the initial-value problem (IVP) for the functional-differential equation of neutral type

$$
x^{\prime}(t)=f\left(t, x(t), x(g(t, x(t))), x^{\prime}(h(t, x(t)))\right),
$$

with the initial condition

$$
x(0)=x_{0}
$$

Here $f(t, x, y, z), g(t, x)$ and $h(t, x)$ are continuous functions with $g\left(0, x_{0}\right)=h\left(0, x_{0}\right)=0$. We assume further that the algebraic equation $z=f\left(0, x_{0}, x_{0}, z\right)$ has a real root $z_{0}$, and we require that

$$
x^{\prime}(0)=z_{0} \text {. }
$$

Existence theorems for IVP's for equation (1) have been proved by R. D. Driver [1] for the case where $h(t, x)<t$, and recently by V. P. Skripnik [2] under the hypotheses that $f$ is sufficiently small, $h(t, x)$ is independent of $x$, and $f$ is linear in the argument $x^{\prime}(h(t))$. Our existence theorem requires none of these hypotheses. Under some additional conditions we obtain a local uniqueness theorem, and obtain as a corollary a result on existence of continuous solutions of certain nonlinear functional equations.

2. Existence. Let $\alpha>0$ and let $J=[-\alpha, \alpha]$. We shall make the following assumptions concerning the IVP (1)-(2a)-(2b):

(i) $f(t, x, y, z)$ is continuous in some region in $R^{4}$ containing

$$
P=\left\{(t, x, y, z):|t| \leqq \alpha,\left|x-x_{0}\right| \leqq \beta,\left|y-x_{0}\right| \leqq \beta,|z| \leqq M\right\}
$$

where $\alpha, \beta$ and $M>\left|z_{0}\right|$ are positive constants. We assume that $\alpha \leqq \beta / M$ and that $\sup _{(t, x, y, z) \in P}|f(t, x, y, z)| \leqq M$.

AMS 1970 subject classifications. Primary 34K05; Secondary 34K05.

Key words and phrases. Neutral-differential equations, functional differential equations.

1 Research supported by NSF Grant GP 20194. 
(ii) $g(t, x)$ and $h(t, x)$ are continuous in the projection $\widetilde{R}$ of $P$ into the $(t, x)$ space; $g$ and $h$ both map $\widetilde{R}$ into $J$, with $g\left(0, x_{0}\right)=h\left(0, x_{0}\right)=0$, and $h(t, x)$ satisfies the Lipschitz condition

$$
\left|h\left(t_{1}, x_{1}\right)-h\left(t_{2}, x_{2}\right)\right| \leqq k_{1}\left|t_{1}-t_{2}\right|+k_{2}\left|x_{1}-x_{2}\right|
$$

for all $\left(t_{1}, x_{1}\right),\left(t_{2}, x_{2}\right) \in R$, where $k_{1}$ and $k_{2}$ are nonnegative constants with $k_{1}+k_{2} M \leqq 1$.

(iii) The function $f(t, x, y, z)$ satisfies the Lipschitz condition

$$
\left|f\left(t, x, y, z_{1}\right)-f\left(t, x, y, z_{2}\right)\right| \leqq L_{z}\left|z_{1}-z_{2}\right|
$$

for all $\left(t, x, y, z_{1}\right),\left(t, x, y, z_{2}\right) \in P$, where $L_{z}<1$.

The Schauder fixed-point theorem yields

THeorem 1. Under the hypotheses (i)-(iii), the IVP (1)-(2a)-(2b) has at least one solution which is continuously differentiable on $J$.

3. Uniqueness. In case $h(t, x)$ is independent of $x$, we obtain the following theorem:

THEOREM 2. In addition to the hypotheses of Theorem 1, suppose that:

(iv) $h(t, x)$ is independent of $x$;

(v) f and $g$ satisfy the Lipschitz conditions:

$$
\begin{aligned}
\mid f\left(t, x_{1}, y_{1}, z_{1}\right)- & f\left(t, x_{2}, y_{2}, z_{2}\right) \mid \\
& \leqq L\left\{\left|x_{1}-x_{2}\right|+\left|y_{1}-y_{2}\right|\right\}+L_{z}\left|z_{1}-z_{2}\right|
\end{aligned}
$$

where $L$ and $L_{z}$ are nonnegative constants, with $L_{z}<1$;

$$
\left|g\left(t, x_{1}\right)-g\left(t, x_{2}\right)\right| \leqq L_{g}\left|x_{1}-x_{2}\right|
$$

with $L_{g}$ a nonnegative constant, uniformly in their respective domains.

Then there exists $\gamma_{0}, 0<\gamma_{0} \leqq \alpha$, such that there is a unique continuously differentiable solution of the IVP (1)-(2a)-(2b) on the interval $\left[-\gamma_{0}, \gamma_{0}\right]$.

The proof follows from the contraction mapping principle.

4. Nonlinear functional equations. As a corollary to our existence and uniqueness results, we note that if $f(t, x, y, z)$ is independent of $x$ and $y$, and $h(t, x)$ is independent of $x$, the problem (1)-(2b) has the form of the functional equation

$$
\begin{gathered}
z(t)=f(t, z(h(t))), \\
z(0)=z_{0},
\end{gathered}
$$

where $z_{0}$ is a root of $z=f(0, z)$. Theorems 1 and 2 then yield at once: 
THEOREM 3. Let $f(t, z)$ be continuous in some region in $R^{2}$ containing $P_{1}=\{t:|t| \leqq \alpha,|z| \leqq M\}$, where $\alpha$ and $M$ are positive constants such that $\sup _{(t, z) \in P_{1}}|f(t, z)|<M$, and $M>\left|z_{0}\right|$ where $z_{0}$ is a real root of $z=f(0, z)$. Let $f$ satisfy the Lipschitz condition $\left|f\left(t, z_{1}\right)-f\left(t, z_{2}\right)\right|$ $\leqq L_{z}\left|z_{1}-z_{2}\right|$ for all $\left(t, z_{1}\right),\left(t, z_{2}\right) \in P_{1}$, with $L_{z}<1$. Let $h(t)$ be continuous for $|t| \leqq \alpha, h(0)=0$, and $\left|h\left(t_{1}\right)-h\left(t_{2}\right)\right| \leqq\left|t_{1}-t_{2}\right|$ for $t_{1}, t_{2} \in[-\alpha, \alpha]$.

Then the problem (3)-(4) has at least one continuous solution on $[-\alpha, \alpha]$, and this is the unique continuous solution on this interval if $\alpha$ is sufficiently small.

\section{REFERENCES}

1. R. D. Driver, A functional-differential system of neutral type arising in a twobody problem of classical electrodynamics, Internat. Sympos. Nonlinear Differential Equations and Nonlinear Mechanics, New York, Academic Press, 1963, pp. 474-484. MR 26 \#4008.

2. V. P. Skripnik, On some systems with deviating argument of neutral type, Izv. Vysš. Učebn. Zaved. Matematika 1968, no. 8 (75), 80-87. (Russian)

University of Missouri-Rolla, Rolla, Missouri 65401 